\title{
Understanding the Manufacturing Process of Molybdenum 47.5\% Rhenium Sheet Through Examination of Microstructures at Steps of Processing
}

\author{
Todd Leonhardt and Joseph L. Johnson \\ Rhenium Alloys, Inc. Elyria, Ohio 44256
}

Rhenium and rhenium containing alloys are unique metals with high melting points, high moduli of elasticity, and excellent high temperature mechanical properties. The most common rhenium containing alloy is molybdenum- $47.5 \mathrm{wt} \%$ rhenium $(\mathrm{Mo}-47.5 \% \mathrm{Re})$. The purpose of this paper is to discuss manufacturing the alloy from powder production through finished material. Some of the primary uses of molybdenum-rhenium alloys include rocket motors for the aerospace and defense industries, cardiovascular stents, cathodes for the electronics field, and various other extreme temperature and medical applications. The focus of the study was to examine the physical characteristics of the pure molybdenum and rhenium powders prior to blending and the blended molybdenum rhenium powders through the use of particle size analysis and scanning electron microscopy. The powders were also analyzed as it relates to ASTM Specification B85903 (Standard Practice for De-Agglomeration of Refractory Metal Powders and Their Compounds Prior to Particle Size Analysis). An examination of the die compacted "green" powders, microstructures of the pre-sintered and sintered compact, hot rolled sheet and the annealed microstructure of molybdenum $47.5 \%$ rhenium will also be discussed. The alloy is body center cubic (BCC) solid solution alloy with work hardening rates half that of commercial-purity rhenium. Unlike pure molybdenum, Mo $47.5 \%$ and rhenium have excellent plasticity at both cold and warm temperatures. The primary deformation mechanism of the alloy is mechanical twinning. The mechanical twinning occurs in Mo/Re during both cold and warm working.

This form of deformation enhances the mechanical properties without sacrificing the material's ductility, while maintaining good strength at elevated temperatures. This will also show the results of the study of molybdenum $47.5 \%$ rhenium powder and sheet manufacturing by examining the processing methods, microstructures, and the role that sigma phase plays in processing and the material's mechanical properties. Also discussed are fractography of the mechanical test specimens, and the mechanical properties at both room and elevated temperatures. 